\title{
BALANCING TRADITION AND DEVELOPMENT? EARLY TRIALS OF A METHODOLOGY FOR STUDYING VERNACULAR ARCHITECTURE AND ITS TRANSFORMATIONS
}

\author{
M. Lidón de Miguel ${ }^{1,2, *}$, L. García-Soriano ${ }^{1,2}$, C. Mileto ${ }^{1,2}$, F. Trizio ${ }^{1,2}$ \\ ${ }^{1}$ Department of Architectural Composition, Universitat Politècnica de València, Spain - (malidde, ligarso)@upv.es, \\ cami2@cpa.upv.es, fratri@upvnet.upv.es \\ ${ }^{2}$ Research Centre PEGASO, Universitat Politècnica de València, Valencia, Spain
}

Commission II - WG II/8

KEY WORDS: Vernacular Architecture, Social Transformations, Cooperation, Methodology, Cataloguing, Burkina Faso

\begin{abstract}
:
In the age of globalization, it becomes necessary to assess the possibilities for the conservation of the characteristic identity features of vernacular architectural heritage. The changes undergone in traditional dwellings appear to be on different scales in societies that are considered developed, and in those that are developing, while the idea of development itself can be the main precursor to change. A study underway aims to identify the nature of the transformations occurring both in traditional architecture and in the society that builds it through case studies and to determine the influence of the concept of "development" in these changes, spotting the potential role of cooperation in the conservation of vernacular architectural heritage and its capacity for sustainability. The analysis of the first case study, the village of Baasneere (Burkina Faso), has made it possible to implement a methodology based on the review of literature, quantitative and qualitative research techniques and the use of three types of cataloguing fiches on three aspects (urban, typological, constructive) of dwellings under study. Although it needs to be adapted to the specific characteristics of the new case studies, the methodology proposed has been proven valid in the study of vernacular settings and their transformations and is also expected to be of use in establishing comparisons between different contexts.
\end{abstract}

\section{INTRODUCCIÓN}

Walls built using cement blocks are executed to form a rectangular enclosure which is covered with several modules of steel corrugated sheets. The construction is carried out by members of the family who will live in the house or by local construction workers. This description could well apply to dwellings in any rural area of Africa, America, Asia or Europe.

Transformations like that described above are occurring in settings where vernacular architecture is still built and experienced. At first glance, it could be stated that this is a material change which is taking place similarly in very different parts of the world. It could also be argued that modernization is irrevocably leading to a unification of constructive techniques now based solely on the use of industrialized materials. However, we should question whether it is only the constructive knowledge of a given culture that is at risk (with the consequent loss), conserving the other virtues of the vernacular, or whether, on the contrary, the material transformation is indicative of a deeper change.

The product, the building, has changed, but have the creative processes behind its configuration also changed? The use of natural materials and traditional constructive techniques can be recovered by relearning and updating them, but can the art of creating meaningful habitats be relearnt? That is to say, can we conserve this timeless or innate form of construction shared by a community or is the loss of this value an inevitable sign of development in society?

\subsection{Antecedents}

In one of his early works Professor Paul Oliver summarized the attitudes regarding vernacular shelter adopted up till then: primitivist, historicist, functionalist, technological, formalist, structural, organizational, inspirational and derivative (Oliver, 1969).

In the same text the author questioned the action of architects who studied vernacular construction applying regular architectural criteria without further research. What processes these constructions were a response to, that is to say, what their function and importance are, what they mean, the structure and hierarchy of their spaces, and what this configuration responds to are all questions which require researchers to focus not only on the physical object itself, but more broadly on the society which built it.

The undeniable qualities of vernacular architecture, already identified in the works Native Genius in Anonymous Architecture (Moholy-Nagy, 1957) and Architecture Without Architects (Rudofsky, 1964), were reaffirmed in a complete definition (Oliver, 1969). These were constructions executed within a community, essential to its life and direct expression of itself. They employed the resources available based on the criteria of economy, environment, climate and location, while specific forms were adapted to the community's material, spiritual and aesthetic needs. In addition, the main virtue of vernacular constructions was also expressed: the profound feeling of belonging to a community which they usually inspire.

* Corresponding author 
Contemporary to this definition, House, Form and Culture (Rapoport, 1969) constituted progress in the study of the processes defining vernacular architecture by showing that the design of the dwelling would respond more to the social conventions of the culture building it than to the physical conditioning factors of the surroundings (materials, climate and landscape). This work was one of the first cross-disciplinary investigations on the issue.

A few years later, the great Encyclopedia of Vernacular Architecture of the World showed that these early approaches to the study of vernacular housing had already transformed into a long list of possible research perspectives (Oliver, 1997).

The examination of these processes behind the traditional dwellings was proposed through approaches that were anthropological, behavioural, cognitive, ethical/emic, ethnological, structuralist and transformational-generative. Individually, they defined different lines of study which in most cases were based on the concepts and methods currently used in the fields of anthropology, sociology, psychology and linguistics.

The establishment of these lines of research confirmed the importance of carrying out cross-disciplinary studies which could use tools from different disciplines to obtain a global knowledge of vernacular construction. Conversely, the study of vernacular architecture could provide the keys to understanding the way of life of a given society.

The creation processes of popular architecture, that is, how these buildings, which require no initial plan or specialist intervention, are conceived and take material form within a community, are still a line of research today. This global approach to the study of architecture makes it possible to determine which elements of the vernacular are at risk of disappearing and what can still be conserved despite transformations.

\subsection{Subject of study}

In traditional societies, people build settings as they consider appropriate in accordance with their cognitive ideals, images and styles (Rapoport, 1980), so that these become mediums suited to their lifestyle and activities. In non-traditional societies the construction of what is considered culturally ideal and appropriate is left in the hands of professionals although, indirectly, it continues to be a representation of the way of life of their residents.

As architecture is therefore very closely linked to social matters, considering the conservation of vernacular architectural heritage, it should be remembered that this dynamic heritage is subject to any variation experienced by social groups (Barada, 2014).

If the changes in behaviour of a community are modified due to changes in cognitive values, images or styles, the settings in which these behaviours took place will also change. The built setting will adapt to the new ways of life, and this could be considered an evolution of architecture into a new form of vernacular.

Furthermore, if this change is brusque (due to impositions or external influences which appear suddenly and spread swiftly), it could lead to a failure in capacity for homeostasis (Rapoport, 2003).
In more isolated societies the dynamics of transformation are barely evident as tradition, which is resistant to change, is still of great importance. However, in a world with increasing communication and intercultural connections, what are the possible perspectives in the field of conservation of vernacular heritage? Setting aside the specific characteristics of individual cases two general scenarios can be observed:

In the rural areas of "developed countries" traditional dwellings have been adapted to modern standards of comfort and forms of production. Adaptation has taken place over an extended length of time, so that vernacular architecture has evolved along with technology. In many cases, the conservation of traditional architectural heritage has been guaranteed by regulations referring to the physical appearance of the dwellings. Although residents may have opposed the imposition of this type of measures, in the long term these have proven to be useful tools in the conservation of cultural identity. The changes threatening the maintenance of these places are also social and economic and are related to rural depopulation and changes in the production and support system.

In rural areas in what are known as "developing countries" transformations in some cases seem to affect many aspects within the dwellings. Using the same language as some anthropologists to describe the evolution of societies (Redfield, 1965), the transition is taking place from primitive vernacular architecture to preindustrial vernacular architecture, taking the culture of developed countries as point of reference. This suggests that the idea underlying the transformations of traditional architecture in a developed context is in fact the concepts of "development" and "modernity" themselves, taken as reference for the way of life.

What is at risk of disappearing and what can be conserved despite the changes? To answer this, it is necessary to question the implications of the idea of development in the conservation of vernacular architectural heritage, especially if this idea breaks with all that came before it. Further thought on this would even lead to questioning the suitability of these concepts. As early as the 1960s, authors who were critical of modernity were calling into question the path that architecture was taking, with some even holding that, while technology had to progress, architecture did not necessarily have to do so (Rapoport, 1969). And what if development, as currently understood, leads to a cultural unification which is also not sustainable?

Based on these assumptions, it seems that cooperation, which is one of the tools for development, should involve a thorough review of the concepts of progress and growth and should be examined with the aim of preserving the cultural identity of societies. Thus, it would be possible to recover a real feeling of respect towards others and towards the environment and joint work, in the field of architecture, in the conservation of a sustainable form of construction.

The ways in which vernacular architecture is being transformed in relation to the changes which have taken place in current societies, the influence of the concept of development in these transformations, and the role of cooperation in heritage conservations, will all be examined in a study, of which this paper presents the first evidence of the methodology. 


\subsection{Research approach}

This research aims to study cases of vernacular architecture currently undergoing evident transformation, in different locations. These can be accessed by the authors as the research group they belong to, is carrying out different research and cooperation projects.

As this work is still in the preliminary stages this paper aims to present the methodology followed in the first case study, which will be reproposed following trials in order to adapt it to new case studies.

The first case was the village of Baasneere, in north central Burkina Faso. A stay was made as part of the ConBurkina research project, funded by the Centre for Development Cooperation of Universitat Politècnica de València, to provide scientific and technical support to the NGO Algemesí Solidari. From 2014 this organization has been working on a project for the construction of a secondary school using CEBs as the main construction material. The ConBurkina project made it possible to carry out an initial 15-day-long stay (January 2018) to take part in training workshops on the construction of CEB tile vaults and for raising awareness of earthen architecture among the local population. A second month-long stay in the village (September 2018) made it possible to start the current study, aided by the following tools:

Bibliographical review: Literature on the history and context of the country were studied, and, in particular, the culture of the Mossi, the majority ethnic group in the village of Baasneere. In this respect, the work focused mostly on anthropological studies. One exception to this was Architecture et cultures constructives du Burkina Faso (Kéré, 1995), a compendium of constructive techniques and the forms of grouping characteristic of the vernacular architecture of the different ethnic groups of the country. This work was extremely useful as it allowed a comparison of what is described as typical in Mossi construction and the actual situation.

Quantitative research techniques: This research was based on the cataloguing of cases of dwellings in the village and the quantification of the transformations taking place. The aim was to identify the scope of the changes, what parts of the dwellings were affected, and their distribution within the village.

Qualitative research techniques: Observation of everyday life in Baasneere and interviews with local residents provided information on the uses of the dwellings, the relation between spaces, social hierarchies, routes, rhythms, etc., everything connected with the form of inhabiting born from individual customs, habits and culture.

The first case study showed that a global vision of vernacular architecture and the processes which generate it was possible, as was the identification of the nature of the transformations taking place within it. Although the meaning of these transformations could be discerned, identifying similarities with changes occurring in other societies is a matter for future research. Also to be examined in future research, is the degree of conservation to be expected from our capacity to build sustainable contexts adapted to both natural surroundings and individual culture, as well as the role of cooperation in this topic.

\section{CATALOGUING AND ANALYSIS}

A review of the literature provided information on the history and customs of Mossi society, prior to the stay. This allowed the authors to become acquainted with the ways of life and how these physically translated into forms of social and urban groupings in the village.

Following the traditional configuration of the family, vernacular dwellings are made up of a series of individual round constructions around a central space, which are joined by walls to form a courtyard. As the family grows, so does the courtyard which is eventually divided into several spaces to form a group of courtyards (Figure 1). Further growth of a set of groups would lead to the creation of a neighbourhood within the village. In this case vernacular architecture is made up of different scales which match the different levels of association.

The main aim of this study was to acquire an overall knowledge of the village's domestic architecture, considering both its traditional features and the transformations underway, which involved covering all the scales of its configuration. In order to collate and organize this information, the continuity of elements in the dwelling was divided into three contexts:

A social and urban context, providing information on the relation of the house to its occupants and the rest of the village.

A context of space and uses, providing data on the configuration of the dwelling, as well as its elements, spaces and significance (uses, relationships, routes).

A material and constructive context to study the constructive techniques of walls, renderings, roofs and openings used in the construction of each individual element of the dwelling.

These three aspects were organized into three different fiches to collect data on all levels of the dwelling. A detailed explanation is provided below on the sections of the analysis and cataloguing fiches used.

Original compound (Patio 1)
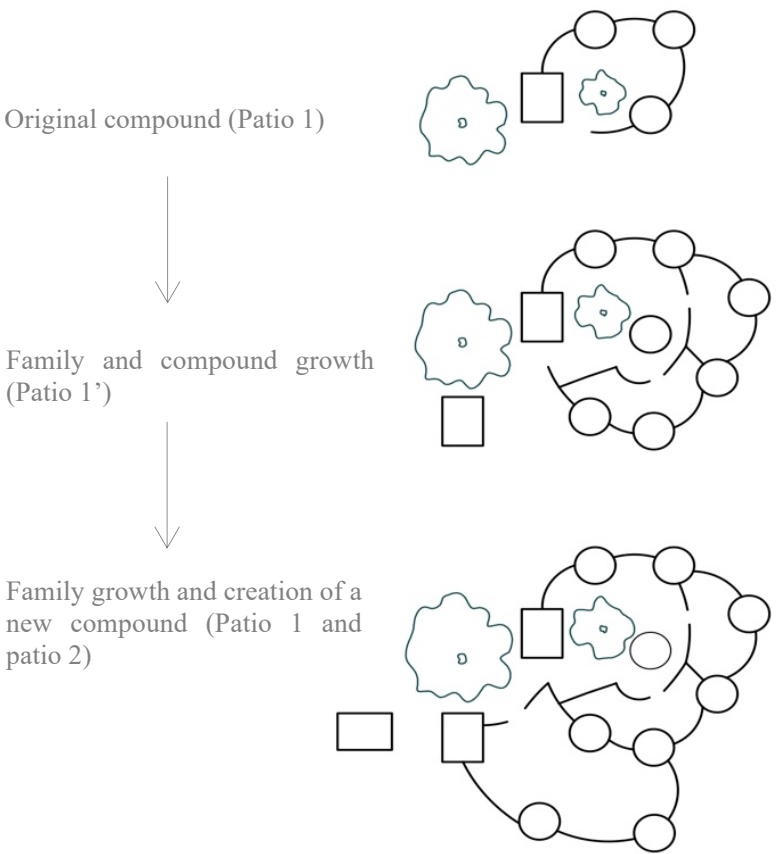

Figure 1. Scheme of the growing process of a traditional house. 


\subsection{FICHE A: Social and urban analysis}

Firstly, this fiche (Figure 2) identified the type of case under analysis: group of courtyards, individual courtyards or dwelling without courtyard. This was followed up with information relating to the location of the case studies within the village and their residents. In this respect it should be noted that the information on owners and their professions was not always available. In fact, it is striking how in most cases the better interactions between the authors and the local residents were made possible in enclosures with a traditional configuration. These dwellings were open and as the courtyards were the central room of the dwelling it was not uncommon to encounter one or several family members on visits to them. It was observed, however, that in interior spaces, individuals tended to be much more reserved so that the owners of the rooms only extended invitations to step inside or have a look on four occasions.

In the case of newer dwellings, both those made up of one or two constructions within a courtyard and independent constructions in the area, it was only possible to establish contact with their residents on a few occasions as the courtyard was closed off in the same way as the interiors. Therefore, in all cases it was only possible to obtain an approximate number of residents rather than an exact figure.

Other data compiled included the distance between case studies and major points of the village such as the road, market or school. The aim of this was to establish whether proximity to these points could have some effect on the transformations of traditional architecture. In addition, the location of the case studies in relation to the path was also helpful for identifying whether these case studies were traditional or recent, depending on their urban configuration. As graphic information an aerial photograph of the case study was included, along with a general image taken during the visit and the general plan of Baasneere (Figure 3).

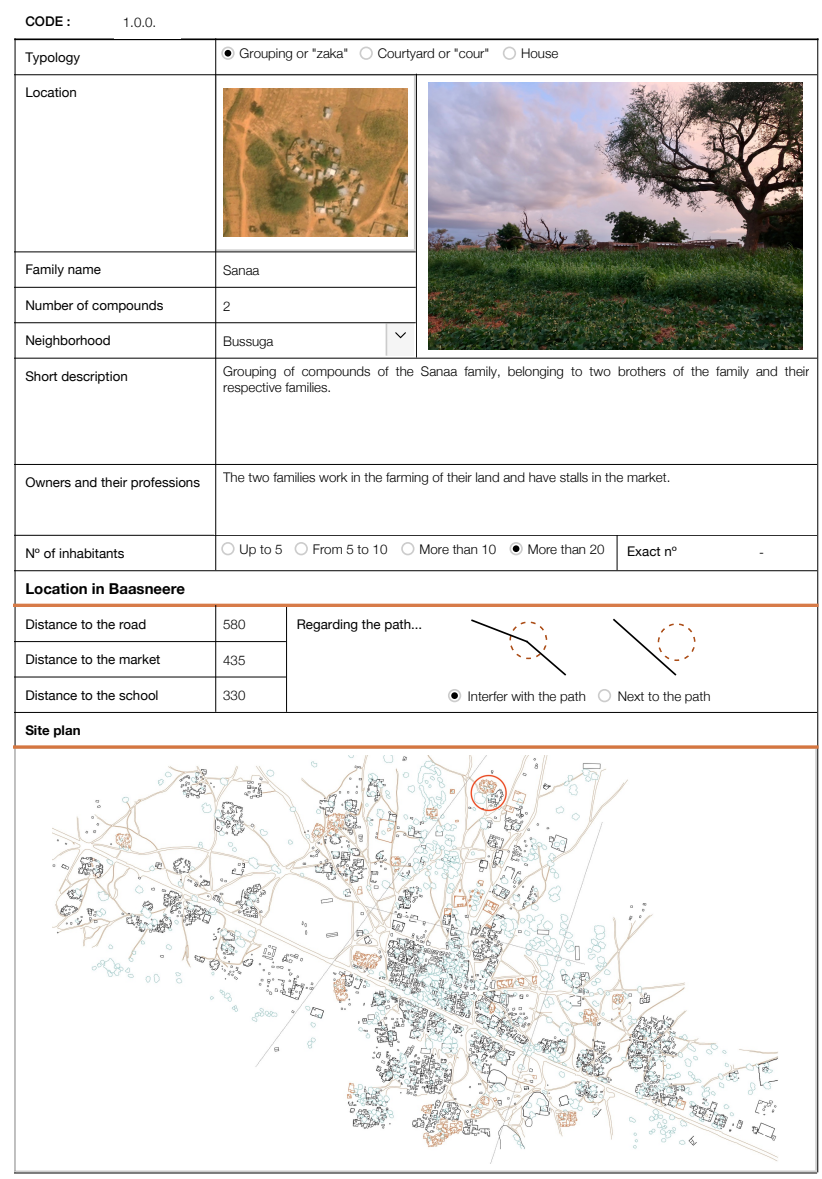

Figure 2. Fiche A: Social and urban analysis

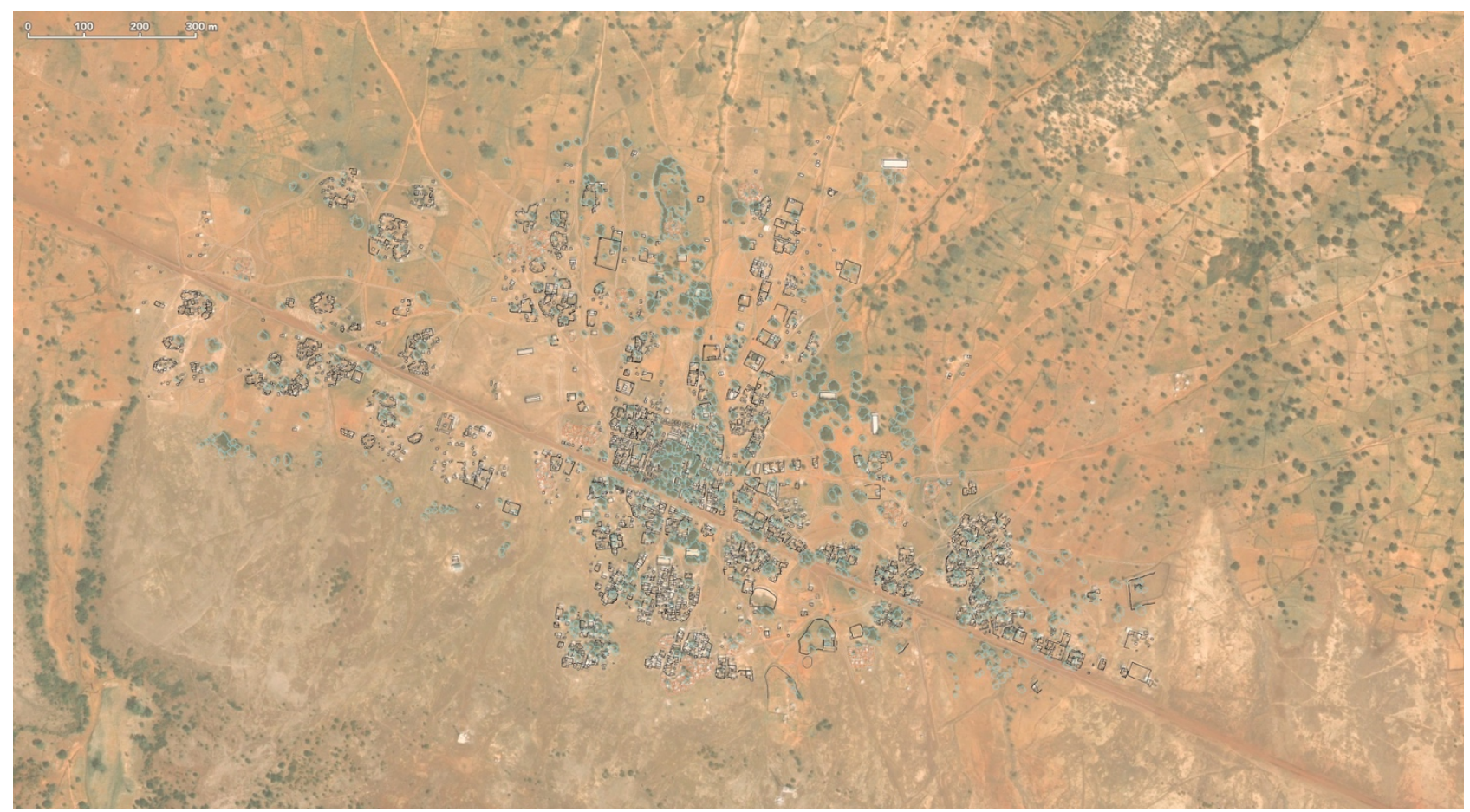

Figure 3. Aerial view and site plan of the village of Baasneere 


\subsection{FICHE B: Analysis of space and uses}

Firstly, the fiche (Figure 4) identified the type of case analysed: courtyard that is part of a group, individual courtyard or dwelling without a courtyard.

Information related to the external (whether or not it was part of a group of elements) and internal (whether or not it was made up of a group of elements) configuration of the dwelling was then collected. In the case of the latter the types of elements and spaces included in every case study were detailed.

- Type of elements: individual courtyards, round constructions, orthogonal constructions, granaries, sheds, kitchens, perimeter walls and entrances. In each case it was established whether or not the dwelling had each type of element and to what extent. The materials used in the construction of walls and accesses were stated to provide information on the nature of these elements and their materials. Information on the construction of round constructions, orthogonal constructions and granaries was not included as it is subject to a more in-depth analysis in the third fiche (Fiche C: Material and constructive analysis).

- Type of spaces: The total surface of each dwelling was measured, establishing a distinction between the total surface dedicated to exterior and interior space. The aim of this was to ascertain the proportion between both spaces and whether it had been varying in recent constructions. The scale of levels of privacy was also studied, identifying if these were directly connected or there were spaces in between. The intention was to study how public and private spaces were being modified as well as the relations between them in the village's architecture.

A general distribution of each case and diagrams of routes, uses, and interior and exterior public and private spaces was included as graphic information. These graphic analyses were very useful for visual comparison showing how each of the aspects in current dwellings was changing.

Finally, a study was carried out of the individual courtyards within the traditional enclosures, identifying how many rooms gave onto them and what the sheds, kitchens, perimeter walls which made them up were like. In this instance it was decided that the case studies chosen should have no more than four individual courtyards. This was generally the case, with only a few exceptions. In this exceptions, the most important individual patios were analysed.

The complexity of some enclosures meant that the individual courtyards were almost the same size as the central courtyards of other cases and, although a more detailed analysis might have been used, data collection had to be limited to complete the research on schedule.
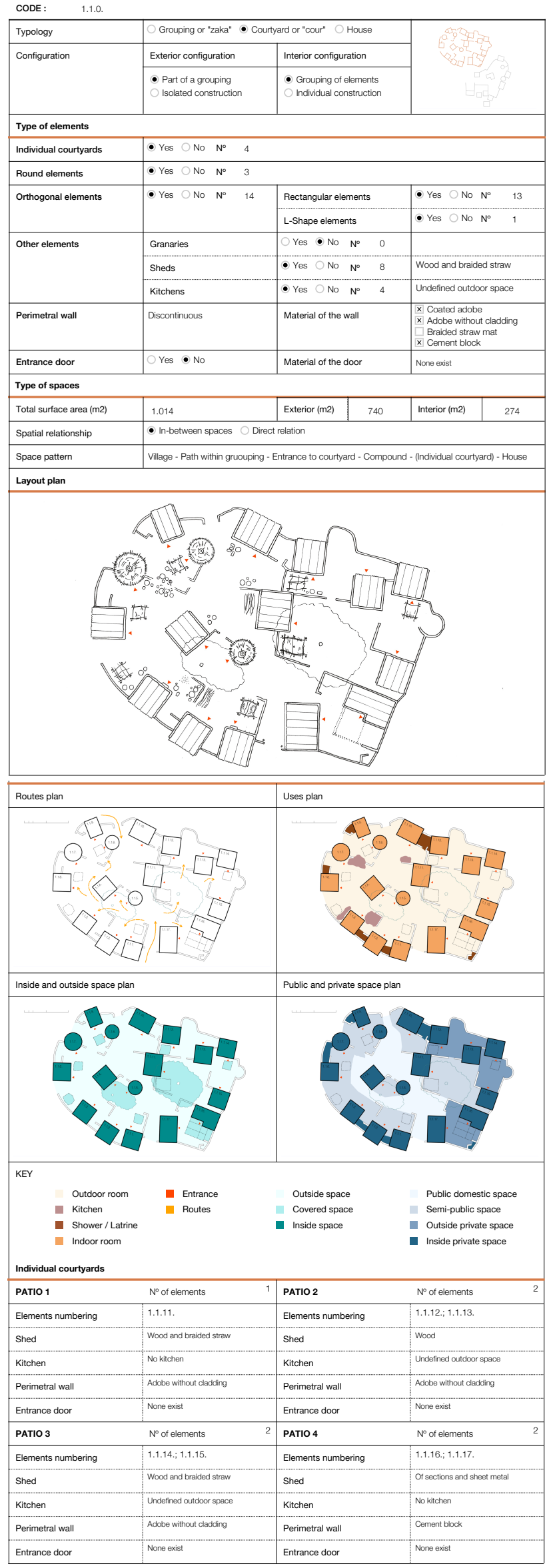

Figure 4. Fiche B: Analysis of spaces and uses. 


\subsection{FICHE C: Material and constructive analysis}

The third analysis (Figure 5) focused on the material nature of the individual elements which made up every room in the case study: rectangular, L-shaped or circular constructions, kitchens and granaries. General data consisted of the main orientation of the building, approximate dimensions and the nature of their execution, that is to say, whether it had been built by the residents or by hired construction professionals.

The state of conservation of the buildings was then indicated. If these were in poor condition it was stated whether the construction was deteriorated, uninhabited or in ruins. If in good condition, it was stated whether the construction was conserved, maintained or new. The criteria followed to differentiate these three options were:

- Conserved construction: Cases in which the repairs carried out ensured good condition, while respecting the original configuration and materials of the construction, using the same constructive techniques.

- Maintained/hybridized construction: Cases in which repairs ensured the good condition of the building, but where new elements, materials or techniques had been used to modify the original configuration of the construction.

- New construction: Recently built cases.

The main part of the fiche focused on the study of techniques and materials used and transformations introduced into the constructive elements for each case (walls, roofs, claddings and door and window openings). For each aspect (techniques, materials and transformations) it was indicated whether it was traditional or new. In addition, for transformations it was also stated whether its scope was general or limited to a specific point. The latter included:

- Replacement: When a new material or technique had been used, edging out the traditional solution, both in older buildings which had been maintained and in new constructions.

- Repair: When the element included recent interventions for conservation, carried out using traditional or new materials and with a limited or more general scope.

- Addition: When the transformation was due to a change in the size of the element.

- Reconstruction: When an element had been redone using new or traditional materials. This type of transformation was difficult to identify as in some cases, where no information was available from the residents of the house, it was difficult to know whether the element replaced an earlier one or if it was part of the original construction.

Finally, information was recorded on other elements of the dwelling including plinths, prefabricated latticework, adobe latticework, blackboards on the wall, solar panels, aerials or drains on the roof. A space was reserved for annotations.

The graphic information included consisted of a small diagram of the location of the construction within the dwelling, a general image of the case study and smaller images of the individual elements analysed (wall, roof, cladding and openings).

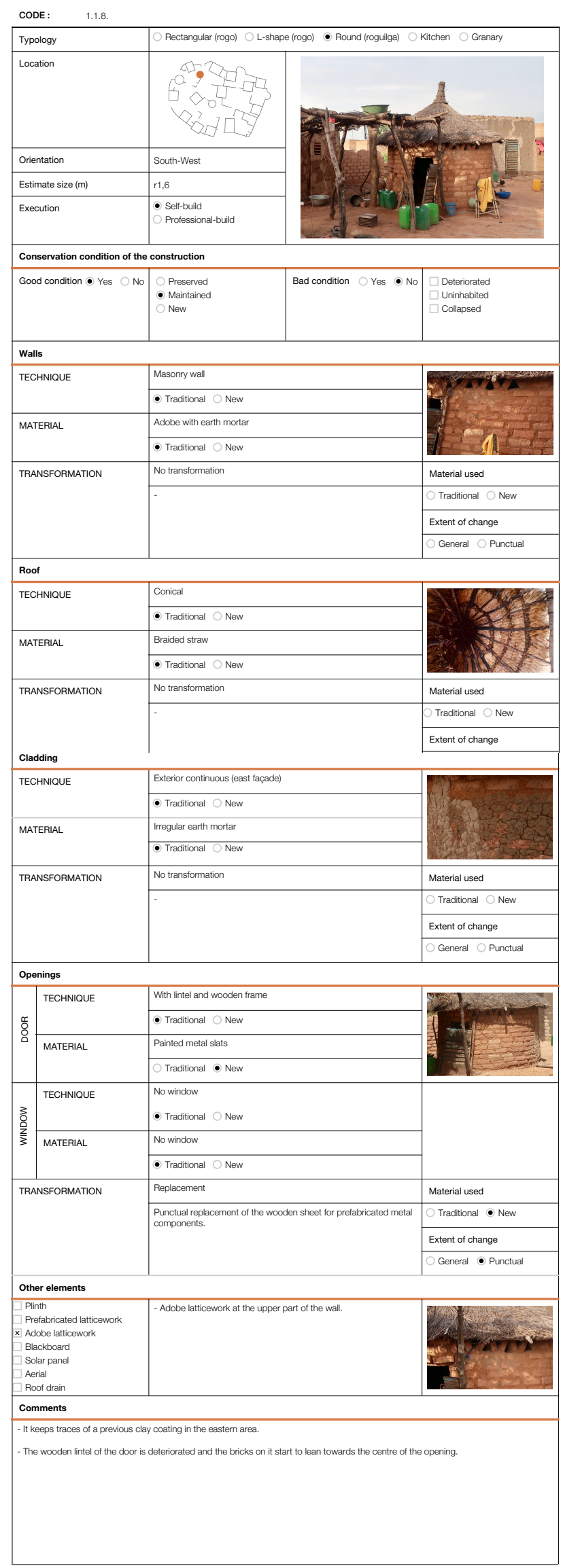

Figure 5. Fiche C: Material and constructive analysis. 


\subsection{Distribution of the sample}

As was explained, each of these three fiches has examined a different level of the dwellings (Figure 6) in each case:

\section{A. Social and urban analysis (70 fiches)}

Of the groups of courtyards.

Of independent courtyards.

Of independent dwellings.

\section{B. Analysis of space and uses (62 fiches)}

Of courtyards from a group.

Of independent courtyards.

Of independent dwellings.

\section{Material and constructive analysis (300 fiches)}

Of individual constructions within courtyards Of independent dwellings.

In order to identify each case easily a three-digit code was used to refer to the group, courtyard, and individual construction respectively.

\section{Group - Courtyard - Individual construction}

Baasneere has approximately 4000 constructions including individual pieces from courtyards, independent houses, granaries and kilns. 300 case studies were analysed of these constructions. Therefore, applying a sample error formula in a finite population the error obtained was $5.4 \%$ with a trust level of $95 \%$. The sample error was considered acceptable for the objectives of this study.

The distribution of these constructions had to be representative of the general situation within the village, so that the case studies chosen were:

- 28 courtyards in groups, made up of 208 individual constructions.

- 21 independent courtyards, made up of 79 individual constructions.

- 13 constructions which were independent dwellings located throughout the area, with no courtyard.

\section{CONCLUSIONS}

The methodology proposed, using fiches for the different scales of the dwelling, has made it possible to identify the changes taking place in the architecture of Baasneere and identifying the aspect of the dwelling in which they are taking place. The study has also led to a type of cataloguing of the constructions of the village, providing detailed information on the characteristics of traditional architecture of Mossi people. Therefore, this research has not only examined the changes taking place, but also the features of Mossi constructive culture themselves.

The fiches employed are useful for organizing the information which can be extracted from a specific case study, thus cataloguing examples of vernacular settings still found today. However, it is true that these fiches should be modified to adapt to the specific variables of new case studies. In this respect, although the three scales for analysis of the dwelling appear to be cohesive and complete, the elements examined in every section may or may not vary between examples. Thus, fiches could be useful for detecting features of the vernacular which do not vary in very different cultures, while they also make it possible to deduce similarities in the transformations taking place.

Analysed critically, the fiches were limited to a study of the social and urban context due to the difficulty of accessing the more recent constructions. The more reserved nature of these new dwellings made it almost impossible to establish communication with their owners, making it difficult to obtain information about the dwelling occupants. However, this limitation speaks to the tendency to create strongly defined limits between the home and public space, a change already identified in other studies on vernacular architecture (Rapoport, 1997).

Can this and other changes be generalized as characteristic of the development of a society? Are we therefore headed towards a cultural unification which will inevitably affect architecture? What means do we have to avoid these processes? These are topics for investigation throughout this research. Learning about the situation we find ourselves in and the trends which will condition the future will make it possible to identify the risks threatening the conservation of vernacular architecture, and especially, our capacity to create sustainable habitats.
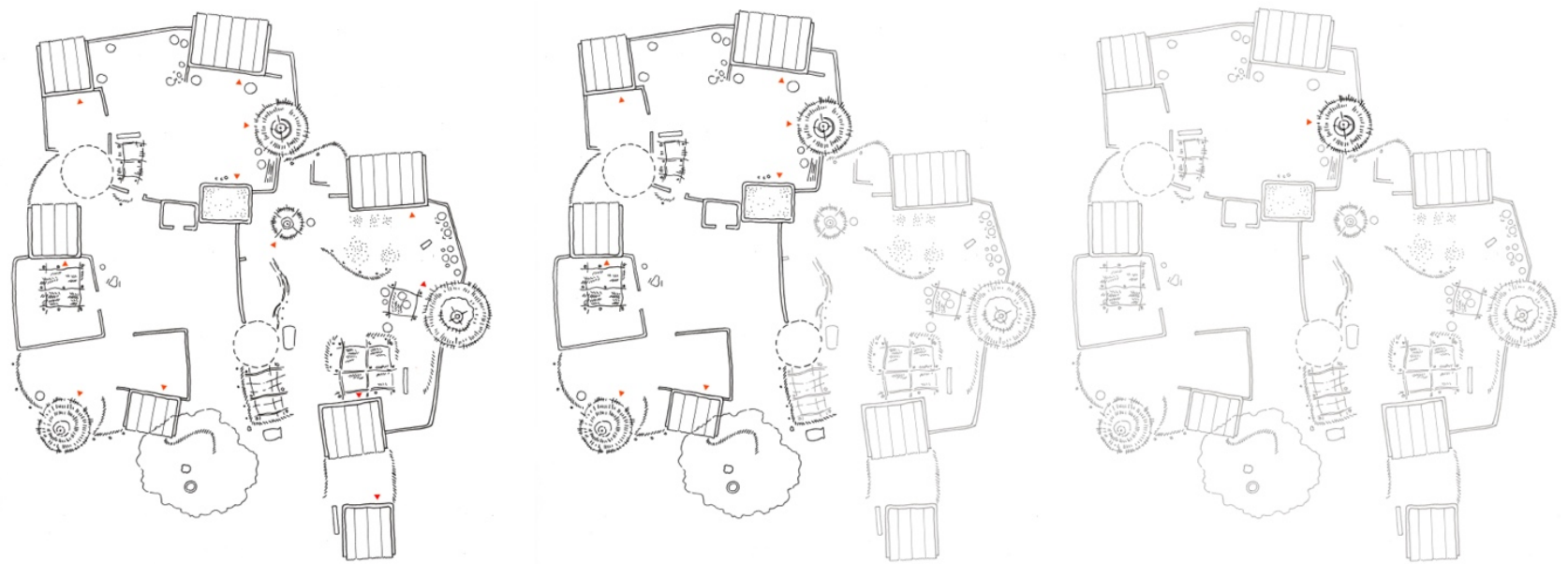

Figure 6. Levels of dwelling in Baasneere. 


\section{ACKNOWLEDGEMENTS}

This research was funded by a grant from the Centre for Development Cooperation of Universitat Politècnica de València, which financed a visit for data-collection to Baasneere. This grant aims to encourage cooperation between the university and associations and NGOs working in international cooperation. In this case, during this visit, the authors collaborated with the project that the NGO Algemesí Solidari is carrying out in the village of Baasneere with its counterpart, A3B.

The authors wish to thank the members of these two associations for their collaboration in the development of the research. They would also like to thank the inhabitants of Baasneere particularly for their welcome and assistance, and particularly Ouedraogo Ismaël, guide and interpreter during the visit.

The initial stages of this research were part of the ConBurkina research project, also funded by the UPV Centre for Development Cooperation, again to support and collaborate with the NGO Algemesi Solidari. Furthermore, the study presented is part of the research carried out for a doctoral thesis funded by an FPU grant from the Spanish Ministry of Education, Culture and Sport.

\section{REFERENCES}

Barada, J., 2014. Transformaciones vernáculas: Cambios y continuidades en las arquitecturas locales de la Puna Argentina. Arquitecturas del Sur, 32(46), 6-17.

Kéré, B., 1991: Architecture et cultures constructives du Burkina Faso. CRATerre-EAG, Grenoble, France.

Moholy-Nagy, S. 1957. Native Genius in Anonymus Architecture. Horizon Press Inc., New York.

Oliver, P., 1978. Cobijo y sociedad (Traductor Corral, J.). Primera edición española. Hermann Blume, Madrid.

Oliver, P., 1997. Encyclopedia of vernacular architecture of the world. Volume 1: Theories and principles. Cambridge University Press, Cambridge.

Rapoport, A. 1969. House, Form and Culture. Prentice-Hall, INC., Englewood Cliffs.

Rapoport, A. 1980. Cross-Cultural Aspects of Environmental Design. Human Behavior and Environment. Volume 4 Environment and Culture. Irwin, A., and Rapoport, A., (ed.), Plenum Press, New York and London.

Rapoport, A. 2003. Cultura, Arquitectura y Diseño. Culture, Architecture and Design. Edicions UPC, Edicions de la Universitat Politècnica de Catalunya, S.L., Barcelona.

Redfielf, R., 1965. Peasant Society and Culture. University of Chicago Press, Chicago.

Rudofsky, B., 1964. Architecture without architects: A short Introduction to Non-Pedigreed Architecture. DoubleDay \& Company, Inc., New York. 